\title{
Evolving a collaborative matrix for teaching informatics online to health sciences students at the Massachusetts College of Pharmacy and Health Sciences
}

\author{
S. King, H. Murray, and K. MacDonald
}

\begin{abstract}
Introduction - The study of informatics is multidisciplinary in nature. The informatics course, HSC 310: Health Care Informatics (HSC 310), for undergraduate health sciences students at the Massachusetts College of Pharmacy and Health Sciences (MCPHS) is an example of a librarian-led, multidisciplinary team functioning within a totally online environment. Description - The development and design of the course HSC 310 is reviewed. Issues and challenges are discussed, as well as the benefits of interdisciplinary expertise in the learning environment. Outcomes - Because informatics is fundamentally interdisciplinary in nature, librarians, instructional designers, statisticians, nurses, pharmacists, and other professionals can learn from each other and strengthen the learning experience of students. The "matrix" of informatics explains how diverse types of information interact with, and impact on, each other. This knowledge is crucial to the understanding of information and its role in one's professional life. There was a journey taken in the design of the course, its evolution cumulating in its final online form. Our unique design was an informatics exercise in itself. Student feedback confirmed that, in addition to the course content, the online environment was a positive educational experience. Discussion - Librarian involvement in teaching informatics at MCPHS began with a National Library of Medicine (NLM) fellowship in informatics at Woods Hole, Massachusetts. This resulted in the library's first for-credit course offered totally in-class and included the participation of faculty from other disciplines. Successful collaboration with the College instructional designer was essential in moving this librarian-led course to a totally virtual environment. In addition, the teaming of librarians with other faculty resulted in two nursing-led, hybrid courses on our Boston and Manchester campuses. During the past two years, interdisciplinary teams have provided informatics instruction to the Boston campus within a totally online environment. This paper discusses one of those courses, HSC 310: Health Care Informatics. The topics discussed in the course and the virtual platform have both provided a valuable learning experience for faculty and students. Informatics is an area where varied disciplines can join to achieve common goals.
\end{abstract}

\section{Introduction}

The field of informatics encompasses many types of information from a variety of sources. However, there are three common principles that are used throughout the field: (1) the identification and gathering of information; (2) decision making and management of information; and (3) the communication of information. The challenge for the Massachusetts College of Pharmacy and Health Sciences (MCPHS) was to find a means to immerse students in an information technology environment that, itself, served as a learning experience for the common principles identified above.

Early development of the informatics curriculum at MCPHS was described in a paper presented to the Canadian
Health Libraries Association (CHLA) in 2008 [4] and a paper published in the Journal of the Medical Library Association (JMLA) [1]. The JMLA paper included a literature review discussing the role of librarians in teaching informatics. That review is still valid and can be accessed at http://www.ncbi.nlm.nih.gov/pmc/articles/PMC385302/.

The initial concept of an informatics course was developed by two reference librarians, Julie Whelan and Mou Chakrabourty. The initial trial elective curriculum was implemented by Samuel King during the spring of 2002 as a classroom-based course with little online support. Although this format provided students with a background in informatics theory, it did not provide them with practical experience. The course coordinator and instructional designer decided that moving the course to an online environment

\footnotetext{
S. King, ${ }^{1}$ and H. Murray. Massachusetts College of Pharmacy and Health Sciences, Manchester Campus Library, 1260 Elm Street, Manchester, NH 03101-1305, USA.

K. MacDonald. Massachusetts College of Pharmacy and Health Sciences, Library and Learning Resources, Instructional Design Services, 179 Longwood Ave, Boston, MA 02115-5896, USA (e-mail: kathleen.macdonald@mcphs.edu).

${ }^{1}$ Corresponding author (e-mail: samuel.king@mcphs.edu).
} 
would create a more authentic, "information rich" environment for students. By providing students with the opportunity to learn informatics skills while utilizing information technology, the act of taking the course itself would be part of the learning content. In addition, because the course coordinator is based in New Hampshire, the online format would provide an opportunity for daily contact with all students. The first fully online informatics course, INF 220: Informatics Issues in Healthcare and Society, was offered on a trial basis during the fall of 2007. It led directly to the course for health sciences students, HSC 310: Health Care Informatics (HSC 310), first implemented in the fall of 2008 .

\section{Description}

In this paper, we discuss HSC 310, a three-credit course offered on an annual basis during the fall semester. It is open to all undergraduate students of the Boston campus Health Sciences program, including students from the Schools of Radiological Sciences, Physician Assistant Studies, and Dental Hygiene. A second online course specifically targeting dental hygiene students has also been implemented. We utilized a multidisciplinary approach using online information technology to create a virtual environment where students can discover the nature of health care informatics.

Informatics has a long history with its growth resulting from contributions from many professions from diverse cultures. One can argue that the Mayan, Egyptian, and Alexandrian cultures, through their fascination with information and the methods for documenting it, were informatics explorers. Certainly Leonardo da Vinci, as evidenced through his calculation machine inventions, was an "informaticist." Charles Babbage invented a prototype of the modern computer during the mid-nineteenth century. One can also argue that those who have utilized a library throughout the past have engaged in informatics practice [1]. Informatics finally emerged as a distinct discipline during the 1950s [2]. This was a direct result of the technological revolution required to win World War II and the emerging challenges of the Cold War. This technology is now being used in a variety of fields, including the education of students to become qualified health professionals.

As evidenced throughout history, no one profession has a monopoly on the practice of informatics. Health-care professionals, computer technologists, librarians, instructional designers, educators, biomedical researchers, administrators, and others all contribute to and participate in the discipline. The study of informatics, therefore, is multidisciplinary in nature. An all-encompassing definition of informatics is the study of issues and systems developed to access information and the process of making decisions utilizing that information. The MCPHS course is based on this definition and is an example of a librarian-led, multidisciplinary team functioning within a totally online environment [3]. Faculty contributors are from the Schools of Nursing, Physician Assistant Studies, Arts \& Sciences, Pharmacy, and the Department of Library \& Learning Resources, representing all three campuses of the College. A deliberate decision was made to focus on "informatics" as an independent discipline, separate from the students' individual courses of study. Our goal was to provide practical and useful information skills, regardless of the students' eventual career paths. Although the content is evolving, the areas covered in 2009 are listed in Appendix 1.

Our strategy utilizes standard Blackboard technology with integrated tools and applications, such as Webcam video and PowerPoint presentations. This model can be easily adapted by other institutions. To create a more dynamic environment, approaching that of a real classroom, we modified the standard Blackboard interface. It must be stressed that the assistance of a skilled instructional designer can prove pivotal in the success of such a significant design modification because the organization and presentation of information in an online environment takes on great significance. Throughout the evolution of our informatics program, the instructional designer was a key member of the design team.

Our new design included three primary features. The first was the creation of a "virtual classroom". This was accomplished by renaming and refocusing the "Documents" folder in Blackboard. Our "classroom" was divided into weekly folders. Each folder contained information about the topic(s) covered during that week. To maintain consistency, each weekly folder also contained identical sections: (1) a short video introduction to the week's topics (created by a desktop Webcam); (2) a folder containing information provided to the students (presentations, readings, and links); and (3) a "Put It into Action" folder containing assignments and other topic-related activities for students to complete. In addition, each week had a unique visual presence, including a separate font and graphic color as well as banner pictures reflecting the topics covered.

The second innovation was the use of the Blackboard Discussion Board for individual student blogs. This was accomplished by creating individual threads for each student where they regularly made posts responding to assigned content-related topics. Because the blogs were individual student commentaries, or diaries, and the focus was their individual reports rather than commentary on other students' posts, we chose to not allow students to reply to the threads of others. The blog forum was contained within the Blackboard, secure from the observation of those outside the course. With this innovation, the restricted threads served as a standard, continuous blog.

\section{Outcomes}

All students who took this course passed, most receiving high grades. Ofthe 18 students enrolled in the course, there were 15 students with an A, 2 with an A-, and 1 with a B+ rating. Faculty observation of assignments and discussions reflected a high student ability to successfully navigate the interface and achieve the learning goals of the course. Four students $(22 \%)$ completed a voluntary course evaluation, conducted through an online anonymous method, providing positive feedback. The results of this survey are presented in Appendix 2. In general, the students believed that they learned from the course. They found the structure of the course to be supportive of the learning process and the grading methods to be fair. Faculty members were also given high marks for their communication skills, 
willingness to assist students, enthusiasm, and knowledge of the subject.

The students also believed that the course provided them with an opportunity to engage in active learning. Some of these scenarios were library-led, while in others, library faculty participated in either a teaching or supportive role.

\section{Discussion}

The interdisciplinary nature of our team was a major strength of this course. The contributions of the instructional designer were of pivotal importance. In an online environment, presentation skills are crucial to the learning experience. Support provided in the design of the classroom banners, general look of the interface, and overall course design options were essential. In addition, support for both faculty and students utilizing the discussion board were extremely important. Ongoing troubleshooting of Blackboard issues by the instructional designer also made for a smooth presentation of the course. The variety of perspectives brought to the table by diverse faculty members enriched the learning experience for students by revealing, in practice, informatics as a product of numerous disciplines. In addition, students were provided a living example of an essential health care skill, working within a multidisciplinary team.

Another important ingredient in the successful completion of an online course is a compliant technology, including effective information technology (IT) support. We faced some challenges during the first running of the course because our particular Blackboard interface was highly detailed and required more lead-in time for preparation than was allowed by our IT department. However, the problem was overcome through collaborative problem solving and the advanced archiving of content. We anticipate a smoother operation this year. Two other technical issues were (1) the difficulty of operating web links from PowerPoint slides once they were loaded into the Blackboard and (2) general email document transfer issues.
These problems were also resolved during the course by utilizing Portable Document Format (PDF) technology and moving to a digital drop box instead of email for document transfer.

The creation of the online course HSC 310 was a wonderfully creative experience for us. We were able to use technology that is currently in broad use to design a unique learning environment that, in itself, personifies the field of informatics. In addition, the course was provided through the positive collaboration among a team of professionals from diverse academic backgrounds. We are now in the preparatory stages for the 2010 presentation of the course and are planning additional features, including live chat, webinars, and other real time activities.

\section{References}

1. King SB, MacDonald K. Metropolis redux: the unique importance of library skills in informatics. J Med Libr Assoc. 2004 Apr; 92(2): 209-17. Available from http://www.ncbi.nlm.nih. gov/pmc/articles/PMC385302/.

2. Cassel LN, Davies G, McGettrick A, Topi H, LeBlanc R. Understanding the entirety of modern informatics. ITALICS: Innovations in Teaching \& Learning in Information \& Computer Sciences [serial online]. 2007 Jul [cited 2010 May 6]; 6(3): 3-11. Available from http://www.ics.heacademy.ac.uk/italics/ vol6iss3.htm.

3. Oldfield SJ, Morse DR. Exploiting connectedness in the informatics curriculum. ITALICS: Innovations in Teaching \& Learning in Information \& Computer Sciences [serial online]. 2007 Jul [cited 2010 May 6]; 6(3): 27-46. Available from http:// www.ics.heacademy.ac.uk/italics/vol6iss $3 . h$ tm.

4. King S. Metropolis revisited: the evolution of an interdisciplinary approach to teaching informatics at the Massachusetts College of Pharmacy and Health Sciences. Paper presented at: CHLA/ABSC 2008. Proceedings of the $32^{\text {nd }}$ Canadian Health Libraries Association Conference. 2008 May 26-30; Halifax, Nova Scotia.

\section{Appendix 1 HSC 310 - Health Care Informatics Course Schedule, Fall 2009}

\section{Week 1}

Presentation content:

1. Introduction to the course.

(Institute of Medicine (IOM) competency focus: - background)

2. Blackboard interface orientation.

(IOM competency focus - background)

3. History of information devices - information technology and the historical impact on health care.

(IOM competency focus - background and all four skills)

Discussion: Orientation to the discussion board.

Assignment: Select project portfolio topic (due Monday, September 21st).

\section{Week 2}

Presentation content:

1. Development and information influence of the Internet.

(IOM competency focus - background)

2. The Internet and its impact on health care.

(IOM competency focus - managing knowledge, utilizing technology to communicate)

Blog entry topic: How does information technology's impact on health care as practiced in 2009 differ from that practiced in 1909 ? 


\section{Week 3}

Presentation content:

1. Creative Internet searching - locating, evaluating and utilizing information.

(IOM competency focus - managing knowledge)

2. Using Web 2.0 resources effectively.

(IOM competency focus - managing knowledge)

3. Selecting, evaluating and utilizing Web based health resources

(IOM competency focus - managing knowledge)

Blog entry topic: Using the resources provided to you on this week's topic, discuss the positives, negatives, and best practices in using Internet based health information.

Assignments: Select and evaluate five (5) consumer web sites which provide information on your project portfolio topic (due to S. King via email samuel.king@mcphs.edu by Monday, September $28^{\text {th }}$ ).

Begin work on your portfolio (Send completed portfolio to S. King via email samuel.king@mcphs.edu by Monday, November 30th).

\section{Week 4}

Presentation content:

1. Utilizing knowledge based resources - searching and utilizing electronic books, journals and other non-print knowledge resources.

(IOM competency focus - managing knowledge)

2. Evidence based medicine (EBM) - researching electronic evidence resources, formulating pertinent questions and making effective EBM based decisions.

(IOM competency focus - managing knowledge, making decisions)

Blog entry topic: Discuss the relative merits of and approaches toward Web 1.0 resources, such as those of the MCPHS collection, and Web 2.0 sources for information on health care.

Assignment: Perform a literature review on your portfolio topic (Monday, October 19th).

\section{Week 5}

Presentation content:

1. Who owns information? (law and practice). What is done and what you should be doing.

(IOM competency focus - managing knowledge, making decisions, communicating effectively)

Blog entry topic: In the downloading environment, who actually "owns" health care information? What is your responsibility? What role does copyright play when you access information as a health care provider?

\section{Week 6}

Presentation content:

1. Displaying information - Making effective PowerPoint presentations.

(IOM competency focus - communicating effectively)

2. Virtual reality and health care - the virtual human project, simulation technology, applications in health care practice and education.

(IOM competency focus - managing information, reducing errors, communicating effectively)

3. Bioinformatics, genomics, and disease - how this information impacts your profession.

(IOM competency focus - managing information, making decisions)

\section{Week 7}

Mid-term quiz.

No presentations. Faculty available for consultation.

No blog topic.

No new assignments.

\section{Week 8}

Presentation content:

1. Electronic patient/clinical systems - from the caregiver and patient's perspective.

(IOM competency focus - all four skills)

2. Diagnostic and therapeutic technologies - the informatics connection.

(IOM competency focus - managing information, making decisions, error reduction)

3. Avoiding errors - drugs and clinical information: a clinician's view of issues related to health informatics.

(IOM competency focus - reducing errors, communicating effectively)

Blog entry topic: What are the positives and negatives of electronic patient/clinical systems?

\section{Week 9}

Presentation content:

1. Information security - impacts and solutions.

(IOM competency focus - reducing errors, managing information, communicating effectively)

2. Health Insurance Portability and Accountability Act (HIPAA) - legal implications of health information. 
(IOM competency focus - reducing errors, managing information)

Blog entry topic: As a caregiver, what is your position and role on the issue of the patient's right to confidentiality as compared to the greater good of the community? 9th).

Assignment: Describe a clinical information system for the area chosen as the term project (due by Monday, November

Week 10

Presentation content:

1. Decision making and its consequences - the impact of "how you use information" on health care, decision support, choices.

(IOM competency focus - making decisions)

2. Decision trees.

(IOM competency - making decisions)

3. Statistics - an informatics perspective.

(IOM competency focus - making decisions)

Blog entry topic: Discuss the impact of decision making in patient care. What issues are at stake? As a caregiver, what are your responsibilities?

Assignment: Develop a decision tree related to your portfolio topic (due by Monday, November 16th).

\section{Week 11}

Presentation content:

1. Distance learning technology - how online learning impacts health professionals and patients (online versus face-toface learning).

(IOM competency focus - communicating effectively)

2. Demonstration of Elluminate classroom.

(IOM competency focus - communicating effectively)

3. Telemedicine - using technology to practice health care from a distance.

(IOM competency focus - all four skills)

Blog entry topic: Compare face-to-face and online learning. What are relative positives and negatives of each method?

Assignment: Describe how distance learning and telemedicine would be used in the portfolio topic (due by Monday, November 23rd).

\section{Week 12}

Presentation content:

1. General systems theory - health care implications.

(IOM competency focus - reducing errors, managing knowledge, making decisions)

2. Informatics from a health systems/organizational perspective.

(IOM competency focus - reducing errors, managing knowledge, making decisions)

Blog entry topic: Explain how information plays a role in how your specific profession relates to other health care professions and your future institution as a whole.

\section{Week 13}

Presentation content:

1. Emerging technologies - "the future is here!!"

(IOM competency focus - all four skills)

Blog entry topic: How do emerging technologies impact your profession? What are the positives and negatives?

Term project due: Submit an online paper with supporting documents on the portfolio topic (due by Monday, November 30th).

\section{Week 14}

Presentation content:

1. Projection: Your profession and future technology - trends and issues - what is the future for health care professions, given current information trends.

(IOM competency focus - all four skills)

2. Course wrap-up (possible live session - face-to-face or teleconferenced).

No blog entry.

Assignment: Study for final quiz.

\section{Week 15}

No presentations. Faculty available for consultation.

Final quiz. 
Appendix 2: Student Survey Results

SHS Didactic HSC 3100 Course Fall 2009 Survey 2009FA 2009
Massachusetts College of Pharmacy and Health Sciences All Schools

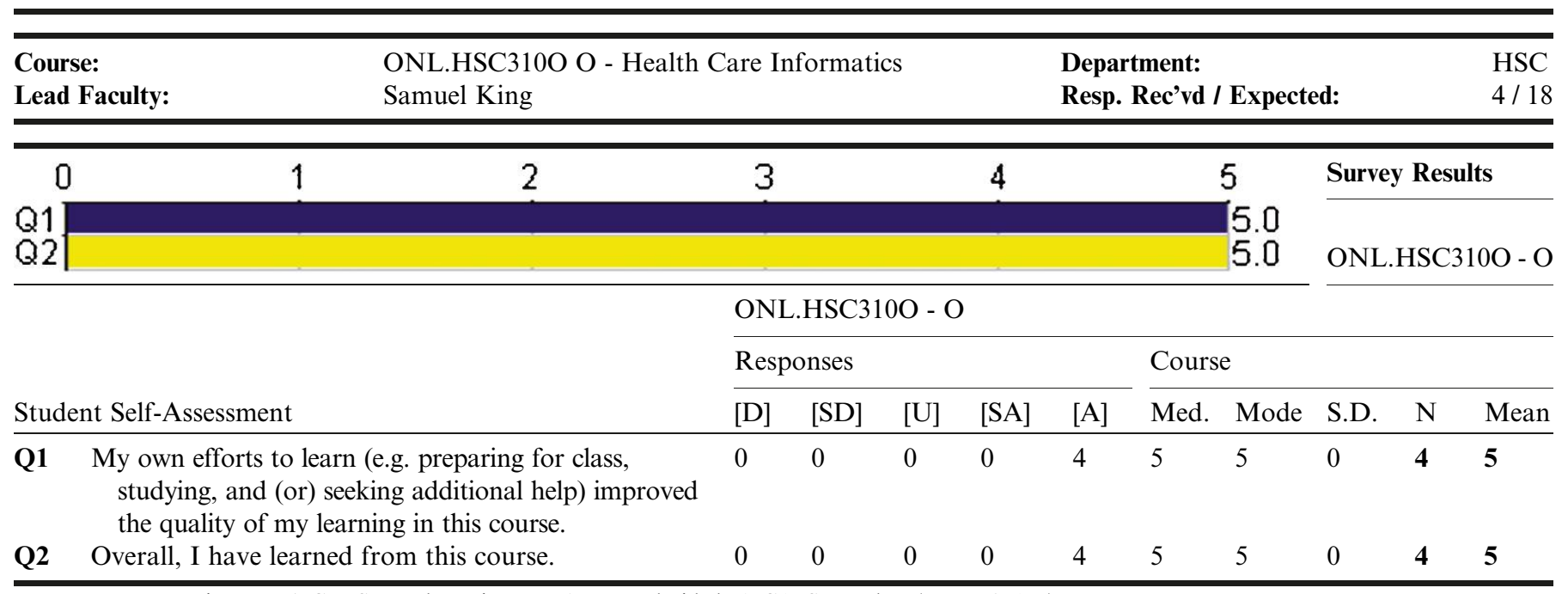

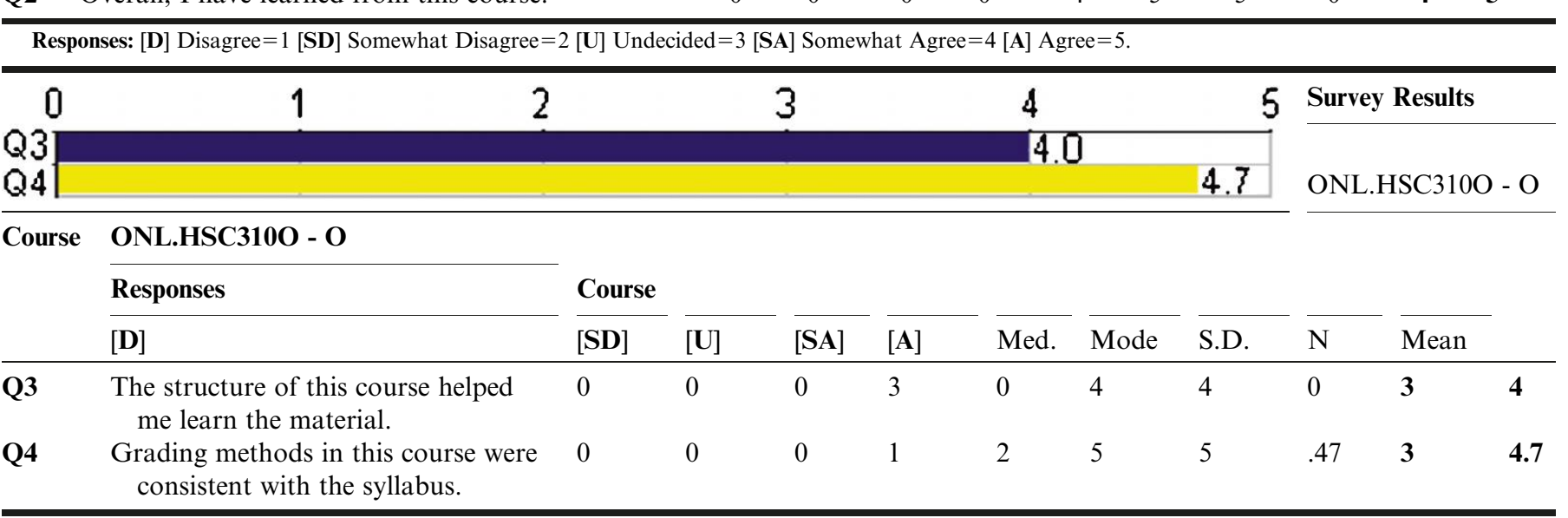

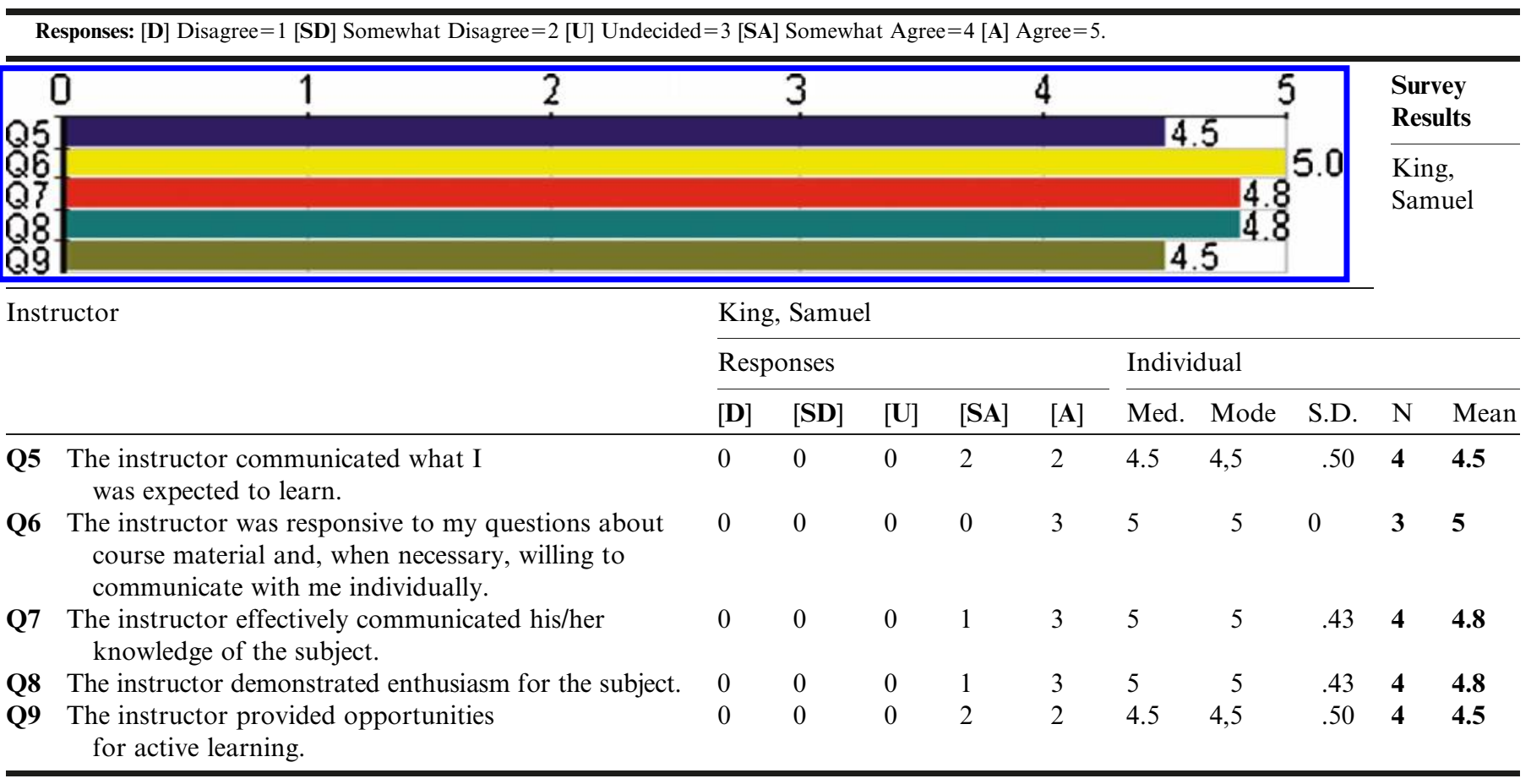

